\title{
Serum lipid concentrations and blood pressure in obese women
}

\author{
R G WILCOX
}

British Medical fournal, 1978, 1, 1513-1515

\section{Summary and conclusions}

In 70 obese women no correlation was found between body weight and serum cholesterol or triglyceride concentrations, but there was a significant correlation between weight and blood pressure. Weight reduction by diet or jejunoileal shunt was not accompanied by any significant change in serum lipid concentrations other than the decrease in serum cholesterol expected after intestinal bypass. Twelve months after bypass surgery was carried out on 14 patients, however, both systolic and diastolic blood pressures were significantly reduced and at levels appropriate to the patients' new weights.

These results suggest that obesity in women cannot be taken to indicate the presence of hyperlipidaemia and that sustained weight loss may lower blood pressure.

\section{Introduction}

Several studies have shown relations between the risk of cardiovascular disease and such characteristics as blood pressure ${ }^{1}$ and serum cholesterol ${ }^{2}$ and triglyceride ${ }^{3}$ concentrations. The contribution of obesity, however, is still unresolved. Data from the Framingham population study ${ }^{4}$ showed that in men but not women obesity or weight gain after age 25 years related to the development of angina pectoris or sudden death but did not predict the development of myocardial infarction. From the results of a seven-country survey of men aged 40-59 years, however, Keys et $a l^{5}$ concluded that in the absence of hypertension, hypercholesterolaemia, and cigarette smoking "no measure of relative weight or obesity made a significant contribution to future coronary heart disease." Nevertheless, an official booklet ${ }^{6}$ suggested that as obesity is easily recognised the practitioner "can assume that there is at least a moderately increased risk of coronary heart disease." Whereas there is little doubt about a correlation between obesity and blood pressure ${ }^{7}$ there is conflicting evidence on the relation between obesity and serum lipid concentrations, ${ }^{8}{ }^{\circ}$ particularly in women. ${ }^{10}$ To resolve some of these uncertainties I examined the relation between blood pressure and serum cholesterol and triglyceride concentrations in a group of moderately to severely obese women and report here the results.

\section{Patients and methods}

The data were obtained from 70 obese women who attended a medical clinic for either dietary advice or consideration for jejunoileal bypass surgery. Mean age was 34 years (range 18-55 years), weight $104 \mathrm{~kg}$ (range $70-153 \mathrm{~kg}$ ), and height $162 \mathrm{~cm}$ (range 150-175 cm). None of the women were taking oral contraceptives or drugs for hypertension when measurements were made, and none regularly

University Department of Medicine, General Hospital, Nottingham NG1 6HA

R G WILCOX, BSC, MRCP, lecturer in medicine drank large quantities of alcohol. Both at the first attendance and before starting energy-restricted diets body weight and right-arm supine blood pressure were recorded and venous blood samples taken for measurement of casual (non-fasting) serum cholesterol ${ }^{11}$ and triglyceride $^{12}$ concentrations. The interassay coefficient of variation for these two estimations in our laboratory was less than $5 \%$.

The effect of weight loss on serum cholesterol and triglyceride concentrations was observed in two small subgroups. In one subgroup 40 patients took part in a randomised double-blind crossover trial to compare the anorectic properties of a fenfluramine derivative and a placebo, both taken in conjunction with a $1000 \mathrm{kcal}(4 \cdot 18 \mathrm{MJ})$ diet. I report the effect of the first eight weeks of the placebo period on body weight and fasting serum lipid concentrations. In the other subgroup 14 patients subsequently underwent jejunoileal bypass surgery (Professor J D Hardcastle), and I report the effect of this procedure on body weight, blood pressure, and casual serum lipid concentrations 12 months after the operation. The preoperative blood pressure used for comparison was that obtained at the clinic visit preceding the patient's call for admission to hospital, as by then the effect on blood pressure of repeat measurements and clinic visits was minimal. Blood pressure was measured at each postoperative clinic visit and the 12-month value used for comparison with preoperative values because by then most of the weight loss had already occurred.

All blood pressure measurements were performed by me, taking the point at which the Korotkoff sounds disappeared (phase 5) as the diastolic blood pressure. Student's $t$ test was used for the comparison of paired data. Results are expressed as means $\pm S E$ of mean.

\section{Results}

There was no correlation between body weight and serum cholesterol and triglyceride concentrations, even in women with massive obesity (fig 1). This was also the case when weight was expressed as either a ratio of height $(\mathrm{cm})$ to weight $(\mathrm{kg})$ or a percentage in excess of ideal weight. There was no correlation between age and either any expression of obesity or lipid concentrations.

Figure 2 shows that the modest reduction in weight that occurred during the first placebo period of the drug study was not accompanied by any significant change in fasting serum lipid concentrations. This

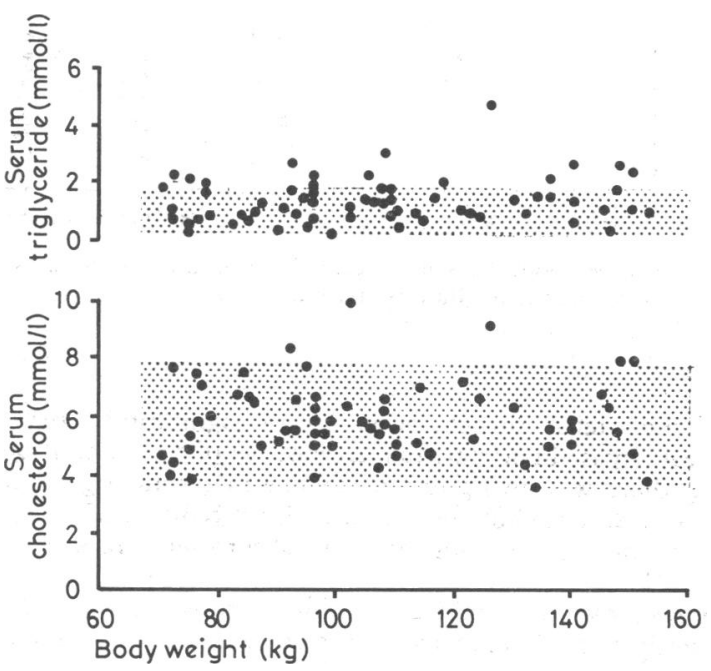

FIG 1-Relation between body weight and serum lipid concentrations.

Conversion-SI to traditional units: Serum triglyceride: $1 \mathrm{mmol} / 1 \approx 88.5 \mathrm{mg} / 100 \mathrm{ml}$. Serum cholesterol: $1 \mathrm{mmol} / 1 \approx$ $38.6 \mathrm{mg} / 100 \mathrm{ml}$. 
was true even for those women who managed to lose a considerable amount of weight during this time. Fig 3 shows the effect of a jejunoileal shunt on weight and casual serum lipid concentrations. The mean preoperative weight in this group of 14 women was $135 \pm 4 \mathrm{~kg}$, which 12 months after operation had fallen to $103 \pm 4 \mathrm{~kg}$. The mean rate of weight loss of $32 \mathrm{~kg}$ during this 12 -month period was of a similar magnitude to that of $5 \mathrm{~kg}$ in two months in the drug study.

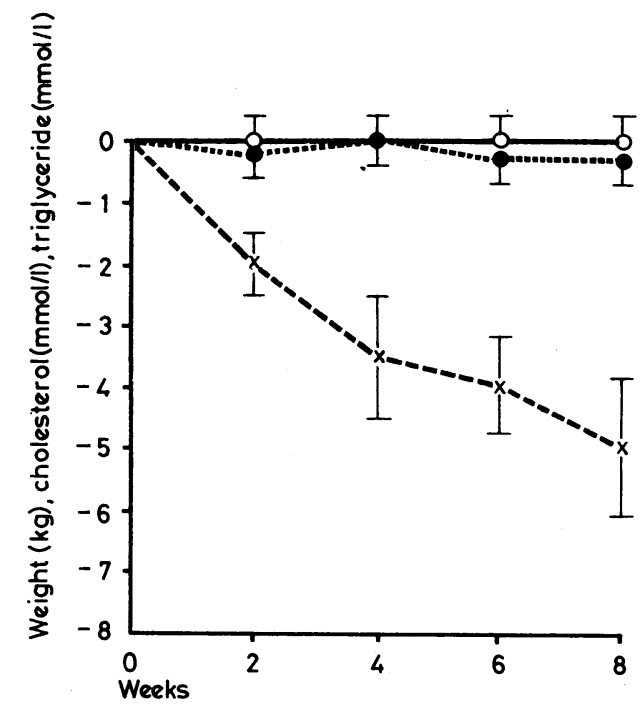

FIG 2-Effect of diet on body weight and serum lipid concentrations in 20 patients. Chart shows mean values \pm SE of mean. $\cdots \cdots=$ Weight. $\times-\cdots--x=$ Serum cholesterol. $\mathrm{O}-\mathrm{O}=$ Serum triglyceride.
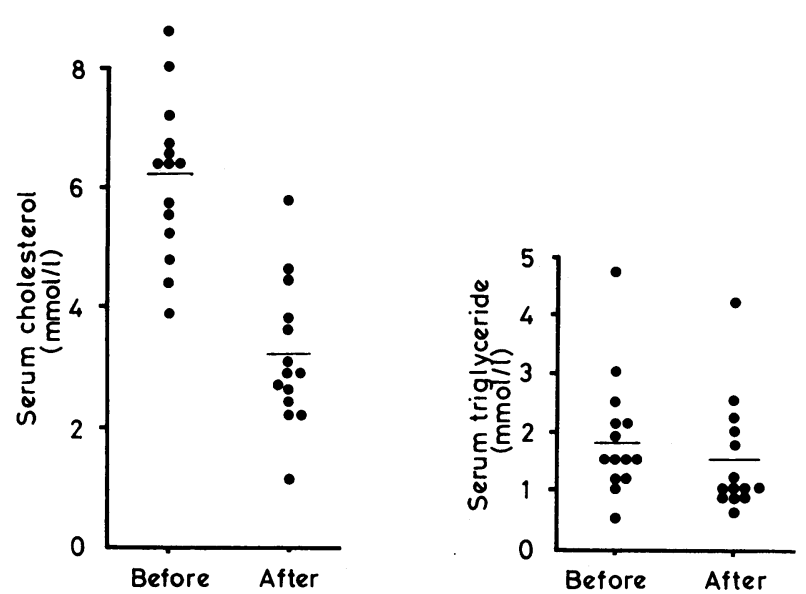

FIG 3-Effect of jejunoileal shunt on serum lipid concentrations in 14 patients 12 months after operation. Bars represent means.

Serum cholesterol concentrations were significantly reduced by jejunoileal bypass in all patients irrespective of the amount of weight lost, but there was no significant change in serum triglyceride concentrations. Serum cholesterol is invariably reduced after jejunoileal bypass because of the bile-acid malabsorption produced by the operation. ${ }^{13}$

Figure 4 shows the significant relations between initial body weight and systolic and diastolic blood pressures in the 70 patients. The mean blood pressure in the 14 surgically treated patients was $151 \pm$ $6 / 93 \pm 3 \mathrm{~mm} \mathrm{Hg}$ before operation and $131 \pm 4 / 82 \pm 2 \mathrm{~mm} \mathrm{Hg}$ at 12 months. These differences were significant for both systolic $(P<0.01)$ and diastolic $(P<0.02)$ pressures. The reduction in weight thus appears to move patients' blood pressures down the regression lines shown in fig 4 to new levels appropriate to the postoperative weights.

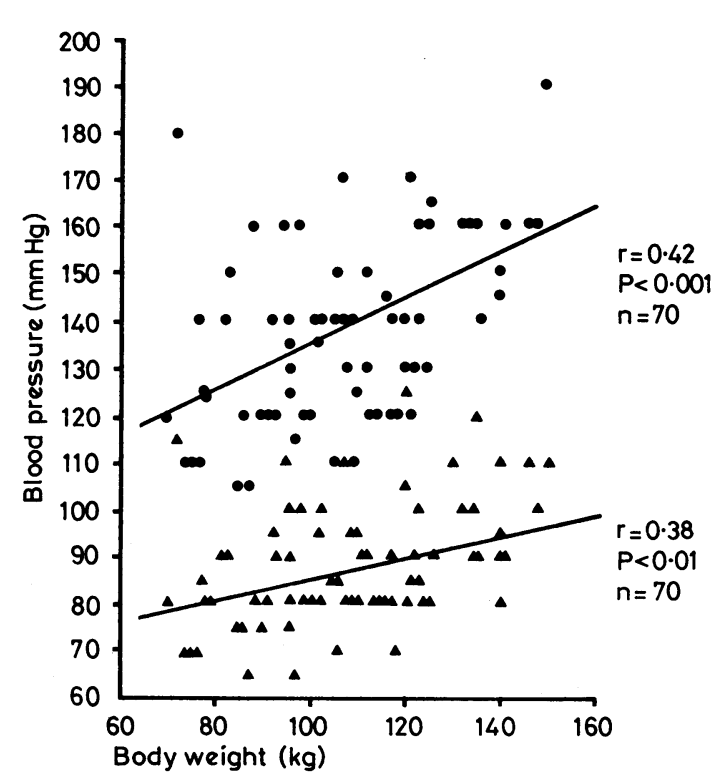

FIG 4-Relation between body weight and blood pressure. $=$ Systolic. $\mathbf{\Delta}=$ Diastolic.

\section{Discussion}

Though difficult to define, obesity is common and easif recognised. It is important, however, to know what assumptions can be made about the presence of other cardiovascular ris factors in obese patients. This study clearly shows that in obese women in the UK there is no association between weight and either serum cholesterol or triglyceride concentrations. Diree measurement is therefore necessary if a cardiovascular ris profile is to be obtained. The numbers were too small to conf ment on the reported increase in serum lipid concentratiog that occurs with age. ${ }^{14}$

The organisation of the clinic was such that fasting lipit concentrations were available only for the drug study. If serum lipid concentrations had increased with increasing weight the the effect and timing of food intake, particularly in relation to serum triglyceride concentrations, would have had to have bee taken into consideration. No such correlation was found, how ever, which makes the results even more significant. This lact of an association between weight and serum lipid concentrations was also reflected in the failure of weight loss to induce a reduction in lipid concentrations. This was true in the shor term drug study for both cholesterol and triglyceride and in the long term after a jejunoileal shunt for triglyceride. This contrasto with patients with established hyperlipidaemia, in whom serum cholesterol and triglyceride concentrations may be lowered weight-reducing diets. ${ }^{15}$ The Australian men taking part $\mathrm{i}$ these studies had a mean prediet weight of $88.6 \mathrm{~kg}$ and conf sumed an average of $26 \mathrm{~g}$ of alcohol daily, a form of excess energy associated with hypertriglyceridaemia. The two studies cannot therefore be directly compared.

The Framingham cohort study ${ }^{16}$ showed that a change i relative weight at each follow-up examination was mirrored by changes in systolic blood pressure and serum cholesterol, serum urate, and plasma glucose concentrations. These changes: however, were small, unrelated to initial relative weight, ang less pronounced in women than men. The influence of the initial concentration-for instance, of cholesterol-on an subsequent change was not stated.

The reported correlation between body weight and bloo pressure is confirmed. "The nature of this relation is unknowe but is no longer thought to be an artefact caused by the large circumference of the fat arm. ${ }^{1718}$ There is little to suggest that weight reduction by diet has any useful hypotensive effect ${ }^{19}$ other than that associated with a concomitant reduction in salt intake $^{20}$ unless the weight loss is substantial. ${ }^{21}{ }^{22}$ Weight loss 
after a jejunoileal shunt, however, unlike that with most dietary regimens, is usually both substantial and sustained, so that the effect of weight reduction on blood pressure is more apparent.

I thank Professor J R A Mitchell for constructive criticism of this paper, Miss Jayne Patrick for typing the manuscript, and the department of clinical chemistry for the biochemical estimations.

\author{
References \\ ${ }^{1}$ Kannel, W B, Schwartz, M J, and McNamara, P M, Diseases of the Chest, \\ $1969,56,43$. \\ 2 Kannell, W B, et al, Annals of Internal Medicine, 1971, 74, 1. \\ 3 Pelkonen, R, et al, British Medical fournal, 1977, 2, 1185. \\ Kannel, W B, et al, Circulation, 1967, 35, 734. \\ 5 Keys, A, et al, Annals of Internal Medicine, 1972, 77, 15. \\ ${ }^{6}$ Report of a Joint Working Party of the Royal College of Physicians of \\ London and the British Cardiac Society, Fournal of the Royal College of \\ Physicians, 1976, 10, 32.
}

7 Boe, J, Humerfelt, S, and Wedervang, F, Acta Medica Scandinavica, 1957, 157, suppl No 321, p 215.

${ }^{8}$ Stamler, J, et al, Circulation, 1962, 26, 672.

${ }^{9}$ Ostrander, L E, and Lamphiear, D E, Circulation, 1976, 53, 152.

${ }^{10}$ Montoye, H J, Epstein, F H, and Kjelsberg, M O, American fournal of Clinical Nutrition, 1966, 18, 397

11 Rappaport, F, and Eichhorn, F, Clinica Chimica Acta, 1960, 5, 161.

12 Lartillot, S, and Vogel, C, Feuillets de Biologie, 1970, 11, No 53, 39.

13 Bruusgaard, A, et al, Scandinavian fournal of Gastroenterology, 1976, 11, 833.

14 Slack, J, et al, British Medical fournal, 1977, 2, 353.

15 Leelarthaepin, B, et al, Lancet, 1974, 2, 1217.

${ }_{16}$ Ashley, F W, and Kannel, W B, Fournal of Chronic Diseases, 1974, 27, 103.

17 Kannel, W B, et al, Annals of Internal Medicine, 1967, 67, 48.

18 Weinsier, R L, et al, American fournal of Medicine, 1976, 61, 815.

19 Mann, G V, New England Fournal of Medicine, 1974, 291, 178.

20 Dahl, L K, American fournal of Clinical Nutrition, 1972, 25, 231.

${ }^{21}$ Keys, A, Henschel, A, and Taylor, H L, American fournal of Physiology, $1947,150,153$.

${ }^{22}$ Fletcher, A P, Quarterly fournal of Medicine, 1954, 23, 331.

\title{
Early deaths in Jamaican children with sickle cell disease
}

\author{
D W ROGERS, JENNIFER M CLARKE, LENA CUPIDORE, ANGELA M RAMLAL, B R SPARKE, \\ G R SERJEANT
}

British Medical fournal, 1978, 1, 1515-1516

\section{Summary and conclusions}

In Jamaican children with homozygous sickle cell (SS) disease diagnosed at birth two-year survival was $87 \%$, compared with $95 \%$ in children with sickle cell-haemoglobin C (SC) disease, and $99 \%$ in normal controls. Death among those with SS disease occurred most often between the ages of 6 and 12 months. Principal causes were acute splenic sequestration and pneumococcal infection.

Neonatal diagnosis of haemoglobinopathies must be followed by close observation if mortality is to be reduced by early diagnosis and treatment of these complications.

\section{Introduction}

Mortality from homozygous sickle cell disease shows considerable geographical variation. In some African populations with a high prevalence of sickle cell trait the rarity of sickle cell (SS) disease in adults can be explained only by high childhood mortality among homozygotes. ${ }^{12}$ In the Belgian Congo (now Zaire) the Lambotte-Legrands ${ }^{3}$ followed 300 children diagnosed at a mean age of 1 year 5 months and reported that $120(40 \%)$ died before the age of 2 .

Higher living standards and improved health care may contribute to the improved survival of homozygotes in North America, but early mortality remains high: Porter and Thurman ${ }^{4}$

\footnotetext{
MRC Laboratories (Jamaica) and Department of Pathology,

University of the West Indies, Kingston 7, Jamaica

D W ROGERS, MRCP, DCH, member of scientific staff

JENNIFER M CLARKE, MRCP, DCH, member of scientific staff

LENA CUPIDORE, SRN, SCM, member of scientific staff

ANGELA M RAMLAL, DM, DCH, member of scientific staff

B R SPARKE, MB, DCP, lecturer in pathology

G R SERJEANT, MD, FRCP, director of MRC Laboratories
}

reported a $16 \%$ mortality in the first year of life among 64 infants diagnosed before the age of 1 . Actual mortality rates may exceed this, since infants die before SS disease is suspected. ${ }^{5}$

Survival of patients with SS disease to adult life is common in the West Indies, but childhood mortality has not been estimated. A cord blood screening programme, started in Jamaica four years ago, has attempted to identify all newborn cases of SS disease in a maternity hospital with about 14000 deliveries a year. Follow-up of these infants has made it possible to calculate a survival curve and to monitor the causes of death.

\section{Methods}

Since July 1973 cord blood samples from Victoria Jubilee Hospital, the main government maternity hospital serving Kingston, have been screened by haemoglobin electrophoresis. ${ }^{6}$ The diagnosis of SS disease was based on the presence of only haemoglobins $(\mathrm{Hb}) \mathrm{S}, \mathrm{F}$, and $A_{2}$ on electrophoresis on both cellulose acetate and agar gel, an $\mathrm{Hb} \mathrm{A}_{2}$ level below $3.2 \%$ at 1 year to exclude sickle cell- $\beta^{0}$-thalassaemia, " and family studies whenever possible. A probable case of sickle cell hereditary persistence of $\mathrm{Hb} \mathrm{F}$ ( $\mathrm{Hb} F$ level of $39.3 \%$ at 1 year; greater than 2 SD above the mean for children with SS disease) was excluded from the study although confirmatory family studies were not possible. The diagnosis of sickle cell-haemoglobin C (SC) disease was based on two major haemoglobin bands in the position of $\mathrm{Hb} \mathrm{S}$ and $\mathrm{Hb} \mathrm{C}$ on electrophoresis on cellulose acetate and agar gel.

From July 1973 to January 197632000 cord blood samples, representing samples from $92 \%$ of all deliveries, were screened, and 109 cases of SS disease and 67 cases of SC disease were detected.

These patients together with 230 age- and sex-matched controls with normal (AA) haemoglobin born in the same hospital were followed prospectively in a special clinic at the University Hospital of the West Indies. Defaulting patients were visited at home when possible. The surviving children were aged from 2 years to 4 years and 6 months on 15 January 1978, the date on which the analysis was based. Survival curves were calculated by the method of Berkson and Gage as described by Armitage. ${ }^{8}$ The method assumes the same mortality in defaulters as in those successfully followed up. Significance levels were calculated from the log rank test. ${ }^{9}$

Necropsies were performed when possible but otherwise the cause of death was deduced from the clinical history and available records. A detailed pathoiogical report of the necropsies is in preparation. 